\title{
Promising Organizational Practices for Increasing Faculty Gender Equity: A Case Study
}

\section{Prof. Karen J. Horton PE, University of Maine}

Karen J. Horton, P.E. is an Associate Professor of Mechanical Engineering Technology at the University of Maine, and a licensed professional engineer in the state of Maine. She is a Co-Principal Investigator on a National Science Foundation ADVANCE Institutional Transformation Grant to increase recruitment, retention and advancement of tenure-track women faculty members in STEM fields. Prior to her 1997 appointment to the University she was employed as a mechanical engineer at Bath Iron Works in Maine, as a high school mathematics and electronics teacher for the Department of Defense Dependent Schools in Germany, and as a mechanical engineer at the Naval Coastal Systems Center in Florida. Horton is an active member of the Engineering Technology Division and the Women in Engineering Division. She also currently serves the Society of Women Engineers as advisor and counselor to the UMaine collegiate section, for which she received the 2010 Outstanding SWE Counselor Award.

\section{Prof. Amy Fried, University of Maine}

Amy Fried is Professor of Political Science at the University of Maine. Fried is the ADVANCE-Rising Tide Policy Advocate and oversees the Maine Policy Scholar Program at the University of Maine. She is also the co-leader of the Maine chapter of the Scholars Strategy Network.

Fried's political science research largely focuses on the history and political uses of public opinion in the United States. Her major works include "Muffled Echoes: Oliver North and the Politics of Public Opinion," (Columbia University Press) and "Pathways to Polling: Crisis, Cooperation, and the Making of Public Opinion Professions," (Routledge).

Fried provides analysis to a wide range of media outlets. She also writes a biweekly column for the Bangor Daily News, where she also blogs (at pollways.com) on politics, public opinion and public policy.

\section{Dr. Mary Madden, University of Maine}

Mary Madden, Ph.D., is the Director of the ADVANCE initiative at the University of Maine. She is also a Cooperating Research Professor in the College of Education and Human Development. 


\section{Promising Organizational Practices for Increasing Faculty Gender Equity: A Case Study}

Organizational change is hard. Even when individuals in organizations wish to make changes, generating new behaviors and practices is extremely challenging. Since academic institutions are relatively nonhierarchical and prize professional judgments by faculty in their departments, consistent change through the entire organization can be quite hard to achieve. Change can also be particularly difficult when attitudes feeding particular behaviors are based in deeply held cultural stereotypes.

This paper discusses a case study of some promising practices related to improving faculty gender equity, a situation in which some of the most difficult conditions for producing change prevail. The case study we analyze concerns the University of Maine (UMaine), which is in the third year of a five-year National Science Foundation (NSF) ADVANCE Institutional Transformation (IT) grant, and is carrying out proposed activities. We focus on the creation and development of an administrative committee at the institution, the Advancement Initiatives Council (AIC), which provided advice and assisted in generating broad support for the proposal, and is instrumental in implementing change activities. As we explain, the formation of this group consisting of faculty members and high-level administrative staff members, prior to submitting the proposal, has been strategically useful. Its activities and processes have gone through various modifications over time to increase its effectiveness. These shifts in AIC activities demonstrate challenges and opportunities from which other organizations can learn. The cases reviewed describe how researchers presented social science research data about the institution to the AIC, the discussion and immediate outcomes, and the resulting ongoing activities in response to the research.

\section{Background on the organization}

The University of Maine is situated in a small town in a rural part of a sparsely populated state. UMaine has a student population of 11,000 full-time and part-time students and employs approximately 470 tenured and tenure-track faculty members, including about 250 in science, technology, engineering and math (STEM) fields and 60 in the social and behavior sciences (SBS). The percentage of women in all of these fields is below the national average.

NSF ADVANCE IT grants are aimed at making systemic institutional change to recruit, retain and advance women faculty in STEM and SBS disciplines. Institutions across the U.S. have documented the many barriers women face in participating in academic STEM careers; however, identifying and tracking these had not resulted in improved situations at most of those institutions. ${ }^{1}$ Prior to submitting the proposal similar documentation efforts had been ongoing at the University of Maine. A 1992 internal report proposed ways to increase women faculty in science and engineering. In 2003 the Office of Equal Opportunity concluded that for faculty members hired in the 1980's, men were significantly more likely to have been promoted to Professor. One major issue identified in the literature involves the persistence of implicit biases, which are held by both women and men and which lead to individuals privileging male faculty after perceiving them as more competent. Women faculty members are undermined by 
accumulated disadvantages that grow out of gendered behaviors, biased responses to them and local environments that, all too often, are isolating or even more adverse. In 2006 a task force on the retention of women recommended mechanisms for retaining and advancing women. Some policies were changed, including options for faculty to extend their tenure clocks and to work outside of the classroom when life and family circumstances made teaching difficult. These efforts, while important and worthy, were largely ad hoc and difficult to sustain through implementation.

The University of Maine is the largest unit in a seven-campus system in which employment policies and practices are governed by a contract negotiated between the system-wide unionized faculty (AFUM) and the University of Maine System (UMS). Buy-in from AFUM and UMS, which had earlier addressed gender-based wage discrimination and accepted some familyfriendly policies, would be necessary to demonstrate institutional support to the National Science Foundation and to make headway on the project's goals.

Like many academic bodies, UMaine fits the model of a "loosely-coupled" organization, in which it is difficult to coordinate practices. Academic traditions dating back many centuries and based in the practices of European guilds give faculty members a fair degree of autonomy. While administrators can overturn departmental evaluations, these disciplinary assessments are typically given great weight. Moreover, departmental decisions affect the resources faculty members receive and can make working conditions productive or difficult. Faculty members experiencing the latter may leave by their own volition or in response to a negative assessment of their work or personnel decision.

Those most involved with this effort recognized that change must occur at multiple levels, from cultural and individual to rule-based and institutional. As the definition of transformational change offered by Eckel et al. contends, “Transformation (1) alters the culture of the institution by changing select underlying assumptions and institutional behaviors, processes, and products; (2) is deep and pervasive, affecting the whole institution; (3) is intentional; and (4) occurs over time."2 Organizing leadership and stakeholders to design and implement change facilitates transformation.

Intentional Transformation

$$
\begin{aligned}
& \text { Purposefully and incrementally } \\
& \text { alter cultural: } \\
& \text { - Assumptions } \\
& \text { - Behaviors } \\
& \text { - Processes } \\
& \text { - Products }
\end{aligned}
$$

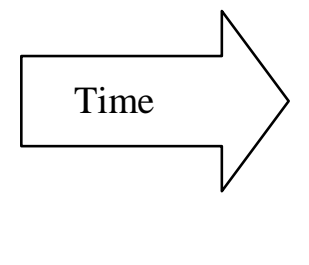

Change that is

- Deep

- Pervasive

Figure 1. The University of Maine interpretation of model for institutional transformation based on Eckel et al.

Initiating the ADVANCE proposal 
Two faculty members, a political scientist and then-associate dean, and an engineer in the School of Engineering Technology, began laying the groundwork for the successful ADVANCE proposal more than a year prior to the submittal date. They approached the provost about the prospect of writing an ADVANCE-IT grant with her named as principal investigator (PI). At that first meeting they considered changes based on the prior work that might be sustainable, whether or not the ADVANCE proposal was successful and funded.

This small, initial core group turned to the experience of other institutions to guide early ideas about the approach. Research suggested that building strong buy-in across campus to the ADVANCE process would improve the likelihood of success. As Fox finds, there are three effective means of supporting effective networks of stakeholders: 1.a coalition of those who can help develop commitment to change; 2 . early and ongoing information about the need for change; 3 . training for participation in change. ${ }^{3}$

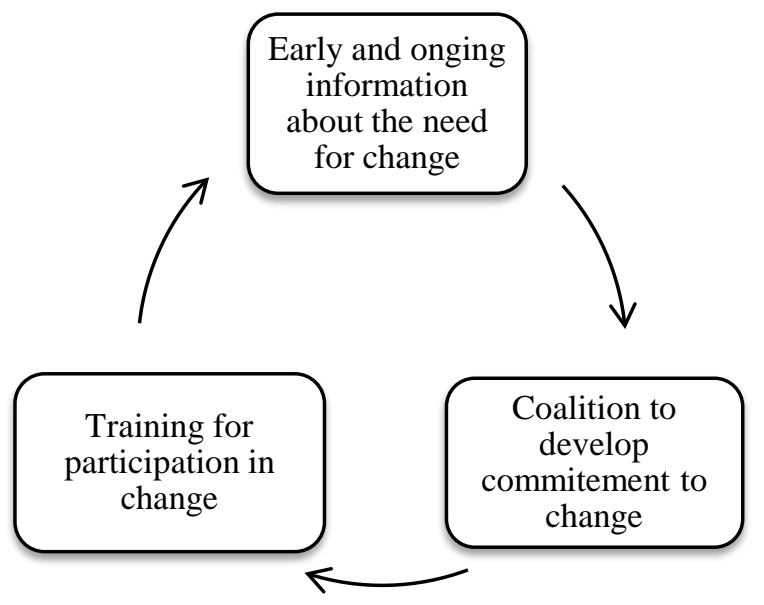

Figure 2. The University of Maine method of develoing and supporting a stakeholder network as suggested by Fox.

The two initiating co-PIs described their idea at the next Provost's Council meeting, which was attended by the Vice Presidents, Deans, and other upper administrators. The goals of the presentation were to help develop early awareness of the issues and gauge support for the idea. The Council encouraged the team to continue. One important next step was recruiting two other individuals to the grant-writing team, a biologist highly familiar with working conditions and climate issues in science departments, and a faculty member of higher education with expertise in gender in institutions. The four core members wrote the grant proposal and were to serve as co-PIs should the proposal be successful, with the provost to serve as the institutional PI.

To provide insight, the team reviewed the pivotal 1999 MIT study regarding the status of women faculty in science, in which MIT President Charles Vest acknowledged that gender discrimination in universities exists and has real impacts. ${ }^{4}$ In particular, the team considered the factors contributing to the policies and practices that MIT ultimately implemented, and possible parallels at UMaine. ${ }^{5}$ MIT had a committed champion frustrated by her circumstances; the UMaine co-PIs would be female faculty members who wanted a more equitable institution. At MIT the champion developed a group of respected women around the issue; at UMaine the Provost agreed to serve as PI and the co-PIs worked to bring on board supportive women already 
fatigued by contributing to earlier efforts. The women at MIT collected data; at UMaine the provost immediately authorized Institutional Studies to support the ADVANCE data collection about the faculty population. MIT women worked with the dean and a committee that included influential men; the UMaine co-PIs also sought a means of connecting with the deans, faculty members, and other influential administrators.

To achieve success, or at least progress, the team realized that it would need to be able to reach diverse faculty members and administrators in many departments to change underlying assumptions about how institutional processes impacted people differently based on their gender. The team would need to connect with the whole institution.

\section{Formation of the Advancement Initiatives Council}

Eight months before the proposal was due, to secure early support for institutional change, the Provost announced the creation of the Advancement Initiatives Council (AIC), an internal advisory board of faculty and high-level administrative staff in the position of implementing changes in policies and practices. Whether or not the proposal was funded, this body was to create an ongoing and sustainable infrastructure for examining institutional policies and practices and planning strategies to further gender equity based on the recommendations of the 2006 task force. The charge stated, "Outcomes will support all faculty members and further the university’s missions of research, teaching and public service.” The AIC would

1. regularly and systematically collect data on rank, promotion, retention, advancement, salary, resources, and space with respect to gender in the tenure-stream faculty;

2. assess the university's academic climate;

3. further routine training for department chairs and administrators responsible for the supervision of faculty, regular exit interviews, and effective mentoring;

4. implement the data analysis needed for the Provost to assure administrative accountability for equitable allocation of resource;

5. regularly assess relevant programs, policies, and outcomes, compare to best practices, and propose new efforts.

The AIC, co-chaired by the deans of Engineering and Liberal Arts and Sciences, met monthly. In addition to the PI team, members included representatives from the faculty, the President's Council on Women, Human Resources, Institutional Studies, Equal Opportunity, the Women's Resource Center, the Office of Administration and Finance, and the Center for Teaching Excellence.

\begin{tabular}{|c|c|}
\hline \multicolumn{2}{|c|}{ Advancement Initiative Council } \\
\hline Co-chairs & Deans of College of Engineering and College of Liberal Arts and Sciences \\
\hline $\begin{array}{c}\text { ADVANCE Grant } \\
\text { Writing Team }\end{array}$ & Provost (PI), Four co-PIs \\
\hline Faculty Members & Six as named by Faculty Senate, President's Council on Women \\
\hline Professional Staff & $\begin{array}{c}\text { Institutional Studies, Human Resources, Equal Opportunity, Women's } \\
\text { Resource Center, Administration and Finance, Center for Teaching } \\
\text { Excellence }\end{array}$ \\
\hline
\end{tabular}

Table 1. Members of the UMaine ADVANCE internal advisory committee 
Immediate benefits of the AIC

Initiating the AIC months before the proposal was submitted helped the PI team develop the necessary institutional commitment to data-driven change. Under direction from the Provost, the Director of Institutional Studies and staff in Human Resources supported the collection of the data recommended in the ADVANCE Toolkit including current headcount of tenure-stream faculty by gender and rank, gender by tenure status, years in rank, and from the previous five years of data, promotion and tenure outcomes, voluntary (non-retirement) attrition, and new hires. Data demonstrating that in all STEM and SBS disciplinary areas the percentage of women faculty members at UMaine was lower than the national average were influential. Over the period studied, in STEM and SBS disciplines there was both a net gain of women, and a net gain in the percentage of women. However, a higher percentage of women than men remained at the Associate level. In addition, thirty percent of STEM women at the associate level had been at that rank for more than six years.

\begin{tabular}{|l|c|c|}
\hline & 2008 UMaine \% Women & 2008 National \% Women \\
\hline Engineering (no Eng. Tech.) & $9 \%$ & $12 \%$ \\
\hline Physical Sciences & $11 \%$ & $19 \%$ \\
\hline Computer Science & $0 \%$ & $17 \%$ \\
\hline Mathematical Sciences & $13 \%$ & $23 \%$ \\
\hline Biological/Life Sciences & $34 \%$ & $35 \%$ \\
\hline Psychology & $33 \%$ & $55 \%$ \\
\hline Social Sciences & $27 \%$ & $36 \%$ \\
\hline
\end{tabular}

Source: NSF (2008)

Table 2: Comparison of UMaine Faculty by Discipline to National Percentages

\begin{tabular}{|l|c|c|c|c|}
\hline & STEM Women & STEM Men & SBS Women & SBS Men \\
\hline Assistant & 16 & 26 & 6 & 5 \\
\hline Associate & 20 & 66 & 6 & 10 \\
\hline Full & 21 & 116 & 4 & 27 \\
\hline
\end{tabular}

Table 3: Rank Distribution of STEM and SBS Faculty by Gender at UMaine

The AIC immediately sponsored the development and administration of an online faculty survey focused on job conditions and satisfaction. A small committee of interested faculty members in the SBS disciplines, the Director of Institutional Studies, and the co-PIs developed this early survey, which included questions from several ADVANCE institutions' climate studies. The ADVANCE social scientist administered the survey and performed the analysis. The campus response rate was $49 \%$; $50 \%$ by STEM women faculty; $57 \%$ by SBS women faculty. Women in STEM and SBS who responded indicated substantially lower satisfaction with career progression and lower satisfaction with the job in general than men.

Five months prior to proposal submittal the co-PIs presented all of the faculty data requested by the AIC, as well as the faculty survey data, in two open workshops with about thirty-five interested administrative, faculty, and staff participants. AIC members were also present as participants. These workshops served to further develop support for data-driven change. Overall the data indicated the need to reduce barriers inhibiting the promotion of women faculty 
members to Professor, and the need to increase the pool of women applicants in disciplines in which the percentage of women falls far below the national average.

Developing these links and structures and gathering data served a number of purposes. For one, the co-PI team identified the need for policies and programs aimed at recruiting, retaining and advancing women, as well as means to reduce isolation and create a positive working environment. In addition, the mix of efforts constituted an intentional and strategic means of tying constituencies, stakeholders, and those who would have to be cooperative (or, better yet, supportive of) transformational strategies to this endeavor of change. Furthermore, the team believed it would help build patterns of support and interaction that would be critical to lasting, sustainable shifts.

As a result of the formation and regular meeting of the AIC, securing letters of support for the proposal was straightforward. The President, Vice Presidents, Deans, the President of Faculty Senate, the Director of the Center for Teaching Excellence, the Vice Chancellor of the University of Maine System, and AFUM officers already had regularly heard about the proposal directly at the meetings, through briefings at other meetings, or directly from members of the AIC. Each wrote a supporting letter.

In addition, upon review of the proposal, the NSF Panel Summary noted that the panel was "impressed" with the initiatives already in place to bring the situation for STEM women to the fore, including the "Provost's council to address STEM issues."

\section{The AIC and the ADVANCE Center}

While the core team and AIC had developed early links and expertise, the period immediately following the award of the grant was organizationally messy. While the grant team had been strategic in how it envisioned and developed the AIC, in that first academic year the AIC was not particularly focused or productive.

What were the problems in the AIC in the first year of the grant? First, the group had a turnover of members, and individuals varied in their knowledge of research on faculty gender equity and issues within the University of Maine. Second, two deans served as AIC co-chairs. The deans' presence was meant to involve top administrative leadership, but the dual position sometimes led to confusion about which co-chair was to do basic tasks (such as providing notes from previous meetings and planning upcoming meetings), as well as setting a broader agenda for the AIC. Third, the group devoted a considerable amount of time to revising its charge and structure. While this proved to be worthwhile in the longer run, some members tired of devoting so much time to this in hour-long meetings rather than focusing on problems and strategies meant to alleviate them.

Two key structural changes this first year put the AIC on a new, more productive course. First, by the end of the first year, the AIC's structure had been modified. Deans continued to serve on the committee, thus building in individuals who hold key positions in the larger institution. However, the co-chair structure was discarded in favor of a single chair. The chair rotates yearly, but the continued service on the committee of the past and incoming chairs helps 
maintain continuity. The second structural change involved the hiring of a permanent director to lead the ADVANCE Center. During the first eight months, a co-PI served as part-time interim director to initiate administrative structures and processes, and support early efforts. The permanent Director hired had been a faculty member at the institution and the internal evaluator for the initiative. In her role as evaluator she had attended several AIC meetings and observed the dynamics and process. Upon assuming the role of Director, she advocated for changes in the AIC with the goal of creating more input and ownership into institutional changes targeted by the ADVANCE grant.

The second year and the AIC

Additional changes in the AIC's operations grew out of the core team's reflections on the first year of the grant and the feedback offered by the external evaluator after a campus visit near the end of year one. The external evaluator made two key suggestions:

"Evidence based decision making. The grant activities call for a significant amount of data collection and self-study. It would be helpful to use this data as a means to present evidence for different campus constituents to consider helping them make their own conclusions and shape future decision making. Such an approach can help to create ownership and also help grant personnel think differently about data and decision making.

Best practices. The campus personnel I met with are poised and ready for change. Many want to do the right thing, but are not always sure what the right thing is. The best practices that have emerged from the other ADVANCE grants are ripe and ready for dissemination. Mining information from other campuses and other projects and then making it available to the University of Maine faculty and administrators would be a good place to start in terms of the dissemination of ideas for how to improve practice to influence faculty retention and career development.”

As year two began, AIC meetings began to be structured to include evidence on campus conditions and broader findings about best practices.

The committee began year two with two half-day strategic planning meetings, which proved pivotal. While the objectives of the grant were set, the strategies to achieve the objectives were flexible and proved to be a key entry point for committee members. Findings from the faculty survey conducted by the social science team prior to the receiving the ADVANCE grant were presented to the committee members after which they were asked to engage in a process of identifying and prioritizing the issues that presented barriers to the recruitment, retention and advance of women faculty. The top issues identified at these strategic planning meetings included promotion and tenure processes, mentoring, and bullying and harassment. These topics became the focus of the remaining AIC meetings, with one issue being addressed at each meeting.

Regular meetings were changed from a monthly one-hour meeting to a two-hour meeting every other month. The longer time frame allowed for a deeper exploration of the issue being discussed. Meetings were structured to include data from the institution and research from the 
scholarly literature and an overview of strategies used by other ADVANCE institutions to address the issue. After these presentations, the AIC engaged in problem-solving, discussing factors that influenced the problem and strategies that had potential to address the problem at the institution.

With the more active role of the director of the ADVANCE Center in working with the AIC chair beforehand to plan the meeting, meetings were more productive. The director identified the relevant data and literature or a member of the institution to present this information, researched strategies, and drafted an agenda. Prior to the meeting, the chair and director met to discuss, revise and finalize the plan. While the director or other faculty or staff person presented the informational portion of the meeting, the chair facilitated the meeting and led discussion. At the end and at various points, the chair summarized the discussion and decisions for the committee.

The new structure enabled the AIC to function better in problem solving and in working with the larger university. At the same time, the director and co-PIs recognized that this success was helped by an idiosyncratic factor: the AIC's chair was a dean who was well-educated about gender issues and had heard a good deal about the project's activities during the period the grant proposal was being developed and written. Moreover, that dean was from a discipline that does research on gender biases and implicit biases.

The AIC's structural changes have been quite productive, by and large. Offered below are two case studies describing motion toward institutional change resulting from the work of the AIC.

Case 1: Improving faculty evaluation

This first case demonstrates the usefulness of the AIC's structure and membership in creating change. Since the institution seeks to improve gender equity, one effort involves making sure faculty evaluations are fair and appropriate. At UMaine promotion and tenure criteria are written at the department level and can be changed only at the initiation of the department faculty. While certain aspects of departmental level evaluation are governed by the AFUM-UMS contract and procedures promulgated by Human Resources, the social science analysis had discovered wide discrepancies in how these were conducted. Certain unit-level approaches opened the door to unfair and inappropriate processes and outcomes.

After an AIC discussion about the different departmental approaches to evaluating faculty, at the end of the first year, the group called for the development of a checklist and accompanying materials on best practices for evaluation. Several departments handling tenure cases in the fall would be asked to use these and the team would gather feedback and then modify the documents for broader dissemination.

This proved to be a learning experience, although not in the way intended. As department personnel were interviewed, it was discovered that departments did not use the materials. Why? One reason was that many believed that their evaluation processes need no changes. However, another reason given was that the request came from the Provost's office, not from the Dean to whom the department reports. One chair straightforwardly said that the Dean is more critical to 
the department, since he is the one who the Chair interacts with more frequently and is more likely to make decisions about resources wanted by the department.

As a result, the AIC learned that it was critical who delivered what messages to whom. Identifying deans as the critical communicators sometimes elevated the importance of deans at the AIC and made it clear that they must be a key element of the project. Since deans and the provost are both on the AIC, the deans know why they are being asked to intervene and explain and they know they are accountable to the provost. Interactions between the ADVANCE team work well in that context.

In following up, a work group discussed training for chairs and departmental evaluation committees and developed a module on fair and appropriate evaluation. One member of this group, a dean, modified the presentation and used it in a chair training session. He also presented it to the other deans at the university. Additional follow-up materials will be developed, with the understanding gained about the critical place of deans in delivering them to units and improving practices.

Case 2: Enhancing knowledge of bullying and harassment

A second example describes the importance the AIC's engagement in dialogue about a problem even when change strategies are not immediately evident. Survey and interview data had revealed that women were more likely than men to experience harassment or bullying from other faculty members. This issue was identified as a priority in the AIC strategic planning retreat and became the focus of a spring meeting.

At the start of an AIC meeting, a member of the social science team whose research explores workplace harassment framed the problem and presented data from the institution. Her presentation prompted a spirited discussion. Many AIC members confirmed the existence of the problem but they lacked suggestions to address the problem. Despite the absence of strategies developed on the spot, this was a productive meeting. Most importantly, it made visible the problem of faculty-to-faculty incivility to administrators at the table.

Once the problem was visible there was space to discuss the problem and explore strategies to address the problem. Using a case study approach, the topic of faculty bullying was integrated into a department chair training session. This sparked a discussion among department chairs about the challenges of addressing this problem and an exchange with the Director of Human Resources (HR) about the realities and possibilities to address the problem. At the training the HR director informed chairs that she could assist them if this was a challenge in their department.

Moreover, several deans who serve on the AIC expressed a need for more training for themselves in how to deal with faculty to faculty bullying in their college. The ADVANCE team is working with Human Resources and the Center for Excellence in Teaching and Assessment to bring a trainer to campus to discuss the issue. So while no immediate strategies evolved from the AIC meeting, the presentation and dialogue highlighted the presence of the problem for all at the 
table including administrators, created space for the conversation to continue and generated the will to continue searching for effective ways to address the problem.

\section{Challenges and Opportunities for the AIC}

While the revised structure and processes of the AIC have been fruitful, leading to key dialogues and the implementation of promising strategies, they are not without challenges. This section outlines some of these challenges and what the ADVANCE team has learned from these challenges.

The revised structure for the AIC leadership, a different dean each year, continues to present some challenges. In year two the strong relationship between the ADVANCE director and dean leading the AIC was fundamental to the AIC's progress. Both individuals came from a social science discipline, spoke a similar disciplinary language, and shared an understanding of how to facilitate change. New chairs will require the director to develop new relationships each year, a process that requires time. It's likely that future chairs will be deans with science and engineering backgrounds, who understand problems in a different way and have different style of leadership. This will require the director to build new relationships each year, a process that takes time and may be bumpy. Mitigating potentially problematic transitions, the outgoing chair has the power to jump start the new relationship by hosting a meeting with all parties to discuss the AIC's process and progress as well as the learning, potential changes, and directions for the upcoming year. The institution could benefit from having all deans be ongoing members of the AIC, and rotating as chairs.

Another challenge presented by the structure of the AIC is that it includes six faculty representatives. Faculty representatives change due to expirations of terms, sabbatical and departure from the institution. New faculty representatives are nominated by their deans and approved by the Faculty Senate. This process for selecting the faculty representatives has resulted in a rotation of faculty members with a range of knowledge and investment in gender equity issues. An orientation meeting for new members helps inform them about the charge and prior work of the committee but does not significantly boost committee members' understanding of and investment in gender equity. Some education is provided on the issue that is at the center of each meeting's discussion, but this is inadequate to enhance a deep understanding of gender issues. While diversity in opinion and thought is valuable to the decisions of the AIC, the inclusion of many faculty members who lack commitment to gender equity has the potential to reduce the AIC's productivity. It is most helpful if faculty members who join the AIC are open to learning and thinking about gender equity issues. PIs and the director have learned they should anticipate faculty turnover on the committee and identify potential new committee members to seek nomination by Faculty Senate who are in key institutional positions and are committed to this work. The participation of new faculty members offers an opportunity to engage a widening circle of supporters.

The range of disciplines from which faculty and administrators on the AIC come provides another challenge. The ADVANCE grant targets faculty in science, technology, engineering, mathematics, and social behavioral science disciplines. In addition, the project has a social science team that investigates barriers for women faculty and institutional change. Faculty and 
deans from these different disciplines often have different approaches to how problems are identified. For example, the physical scientists and engineers on the committee often place a lower value on survey and interview data, the methods often used by the social science and evaluation team to identify barriers and measure the effectiveness of ADVANCE initiatives. Therefore, it should not be a surprise that some time at each meeting is spent critiquing research approaches as well as the validity and reliability of the data used to frame a problem. While cautions about methods or sample size are useful, prolonged discussions deflect from discussing an issue or its potential solutions. The team has learned for discussion to productive, it is best to use a mix of data, including institutional data, to describe problems and to acknowledge limitations of small samples as well as the strengths and limitations of interview and survey data.

A final challenge may seem small but can create problems for implementation. The meetings are structured to place the updates about the ADVANCE program's initiatives at the end of the agenda. This is a purposeful decision to limit the amount of time spent on discussing the updates and to use the majority of meeting time to focus on soliciting generating strategies to best accomplish the goals of the grant. While two hour meetings provide more substantial time than in year one to discuss topics, it's difficult to curtail discussion when members are highly engaged. At times, discussion flow over the allotted time and updates are cut short. This results in AIC members not having adequate information about implementation of strategies which reduces the impact of AIC members as ambassadors for ADVANCE programs. The AVANCE team will consider other options for providing AIC members with updates, such as monthly email updates.

As challenges with the AIC are recognized, the ADVANCE team continues to adapt the structure, processes and strategies for maximizing the effectives of the AIC to serve as a vehicle to solicit input to create investment and ownership and of goals and advocacy for strategies to promote gender equity among faculty.

The external evaluator noted, by the end of the year two, many improvements had been made. Following her second year site visit, the external evaluator reported,

"The Advancement Initiatives Council (AIC) provides key leadership and connection to different campus constituencies. The chair of AIC for 2011-2012 was the Dean from the College of Liberal Arts and Sciences, and he created a strong relationship with the ADVANCE director to provide direction and oversight related not only to grant activities, but also to particular themes that need consideration to implement and support grant activities. The support and active involvement of the AIC was a key accomplishment of the year. AIC members seem highly invested in grant activities and the Council plays a key role in providing direction and oversight in addition to providing a link back to different members of the campus community.”

\section{Conclusion}

Creating the AIC prior to writing the ADVANCE proposal was a strategic step that proved helpful for developing support for the proposed activities and for obtaining the NSF grant. It was an effective means of obtaining support for data-driven change among the administrators 
and staff members who are in the position to help implement change. Other institutions could benefit from this early organizational approach.

In developing the internal advisory committee, the PIs' aims were to build in particular members - deans - who are at key points in the organizational structure, so as to facilitate certain activities. Other organizations might benefit by bringing together as a board a select group of faculty, administrators, and staff members who have the authority to institutionalize new policies and practices. The director and the PIs have been strategic and intentional, adapting the structure as time goes on. While challenges remain, the AIC's structure has been an effective means of guiding and implementing institutional change.

While the core team needs advice from deans and other members, often they also educate them about broad issues and research (statistics about the institution, internal social science research and research in the literature, on topics such as implicit bias, bullying, etc.). As AIC members include several deans and top administrators in the offices for human resources, equal opportunity, and the employee assistance program, along with faculty members, the PIs and director can draw from expertise, knowledge and use members as access points to the institution.

Moreover, AIC members are employed in the delivery of policies, programs, and communications. More broadly, this structure sends a message about the degree to which upper administration, particularly the provost, thinks this project is important. Ultimately, this creates and demonstrates buy-in. In the long run, this structure and its accomplishments create avenues of sustainability, so efforts will be embedded in the institution as much as possible and will continue after the grant is completed. While structures must always be adapted to particular organizational conditions, this case study of the formation, use and development of this internal advisory committee provides a model other organizations and change agents can emulate.

\footnotetext{
${ }^{1}$ Sturm, Susan. 2006. "The Architecture of Inclusion: Advancing Workplace Equity in Higher Education." Harvard Journal of Law and Gender 29: 247-334.

${ }^{2}$ Eckel, P, Hill, B., and M. Green. 1998. On Change: En Route to Transformation. Washington, DC: American Council on Education.

${ }^{3}$ Institutional Transformation and the Advancement of Women Faculty: the Case of Academic Science and Engineering, Mary Frank Fox, Higher Education: Handbook of Theory and Research Volume 23 (pp 73-103). Edited by J.C Smart, Spring: 2008.

${ }^{4}$ A Study on the Status of Women Faculty in Science at MIT. 1999. The MIT Faculty Newsletter, Vol. XI, No. 4.

5 Ibid.
} 